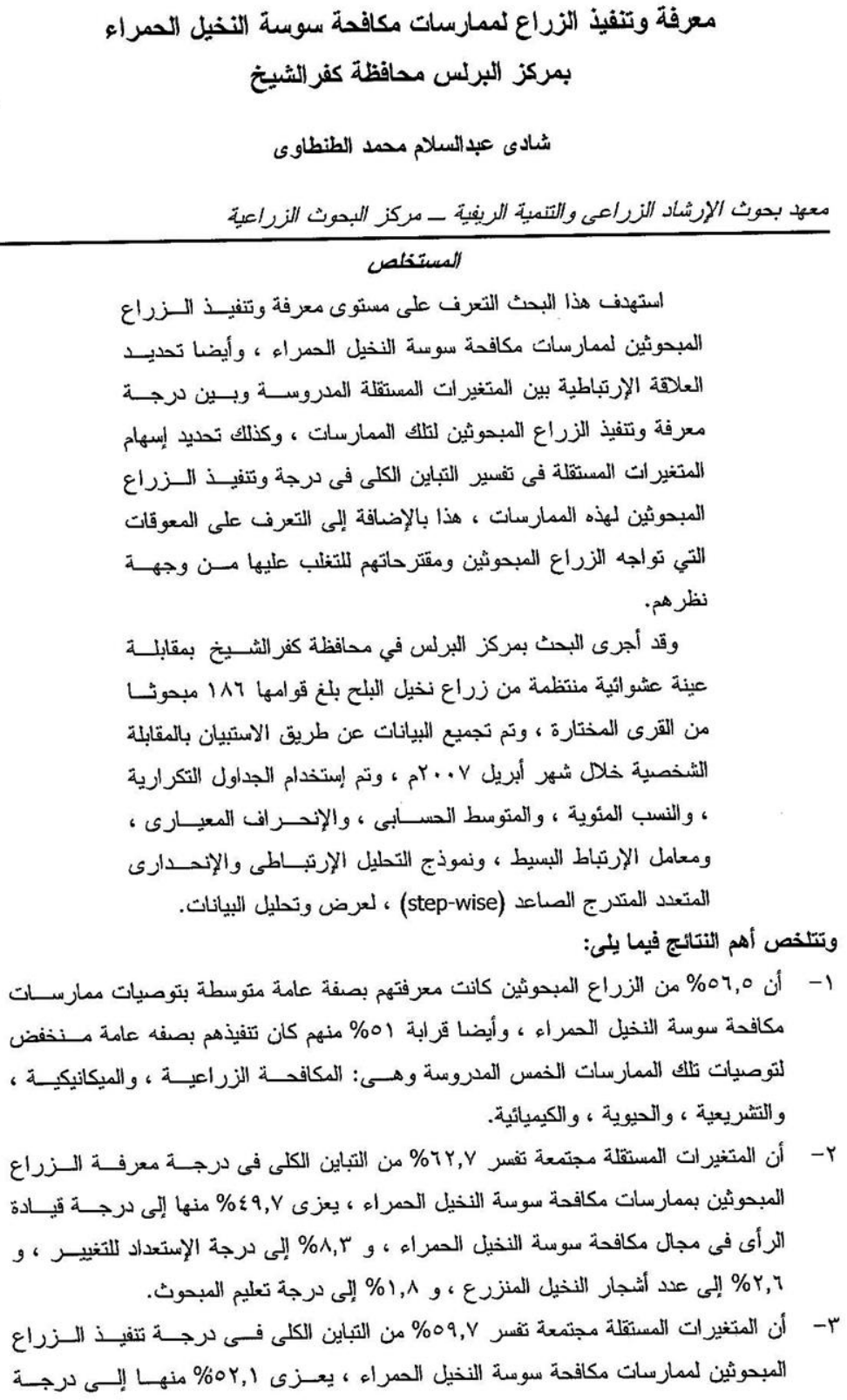




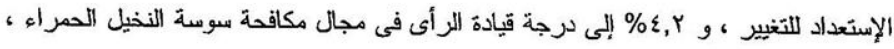

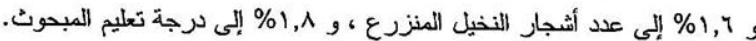

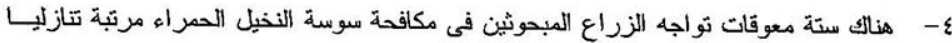

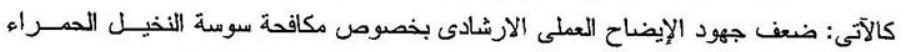

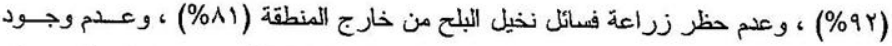

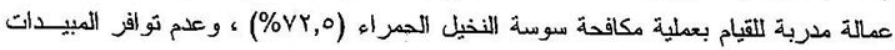

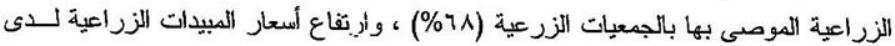

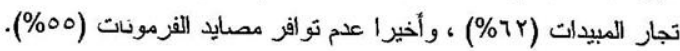

\section{مقدمة ومشكلة البحث}

مما لاشك فيه أن التنمية الزراعية ، تعتمد بدرجة كبيزة على سرعة تدفق و إنسياب الثقنيات،

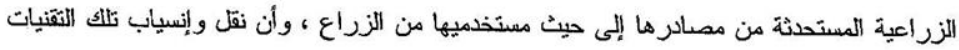

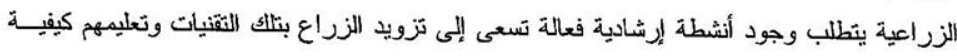

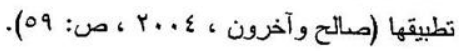

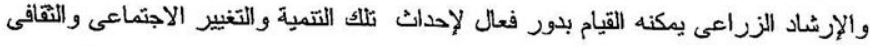

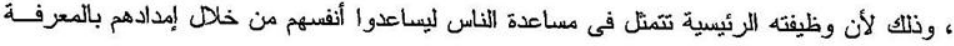

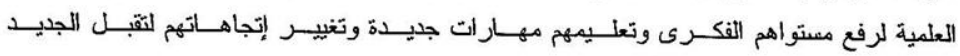

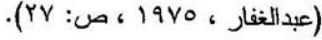

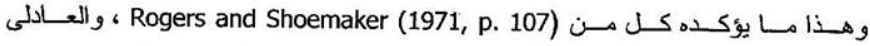

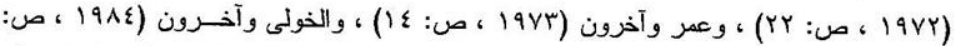

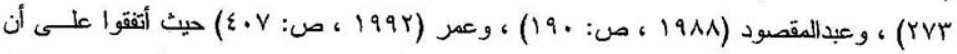

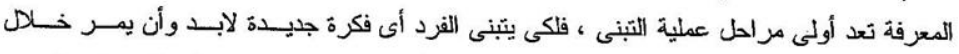

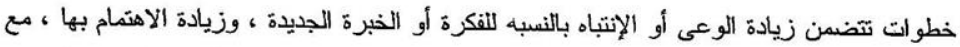

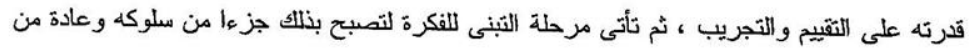
عاداته التتفيذية.

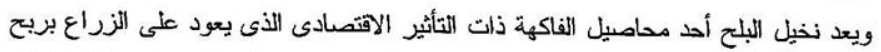
أعلى من المحاصيل التقليدية (حجازى ، سريل19 ، ص: ع V) ، كما يعتبر أحد المصادر الهامة لغذاء

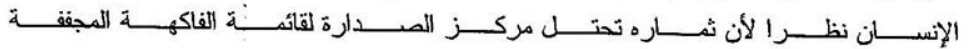

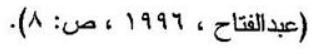

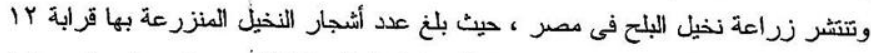

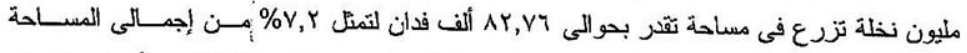

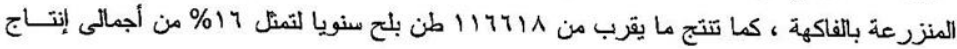

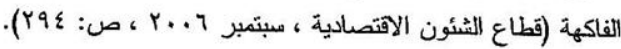


وتتعرض أشجار نخيل البلح للإصابة بالعديد من الآفـات الحشــرية والآكاروســية يعتبّر

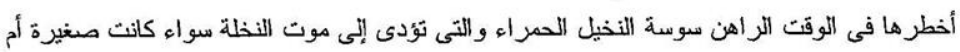

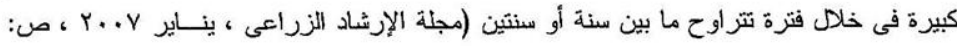

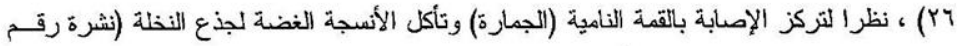

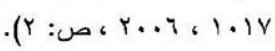

وقد دخلت هذه الآفة إلى مصر عام بو إم ام في محافظة الشرقية لتصيب كن أنواع أشجار

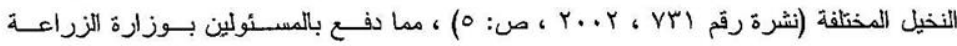

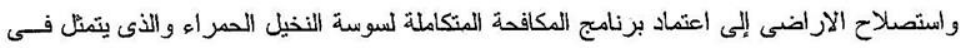

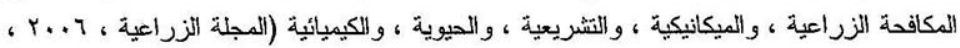

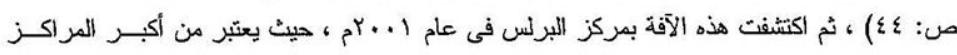

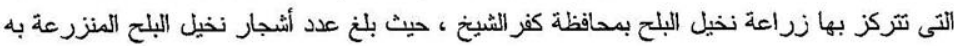

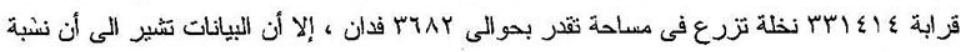

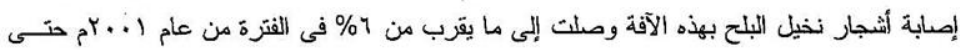

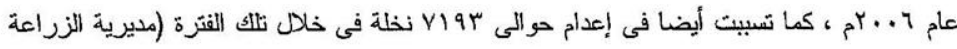

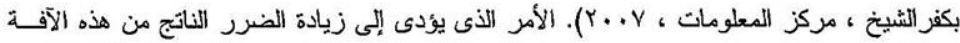

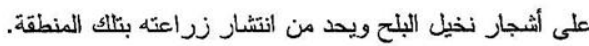

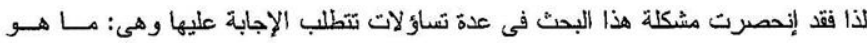

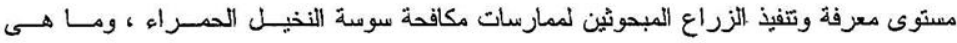

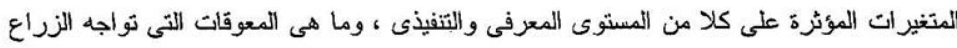

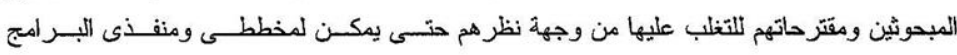

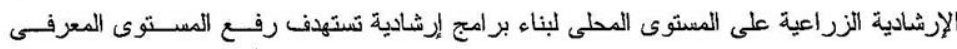
و التنقيذى لززراع نذيل البلح بممارسات مكافحة سوسة النخيل الحمراء.

أهداف البحث

مما سبق يمكن تدديد اهداف البحث فيما يلى:

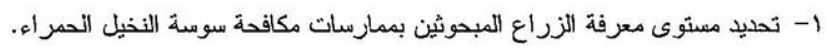
r- ب تحديد مستوى تتفيذ الزراع المبحوثين لممارسات مكافحة سوسة النخيل الحمراء.

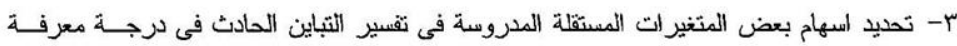
الزراع المبحوثين بممارسات مكافحة سوسة النخيل الحمراء.

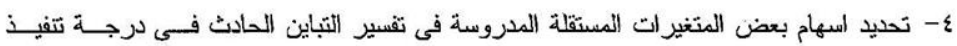
الزراع المبحوثين لممارسات مكافحة سوسة النخيل الحمر اءئ

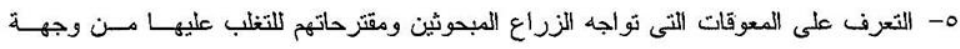

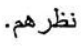




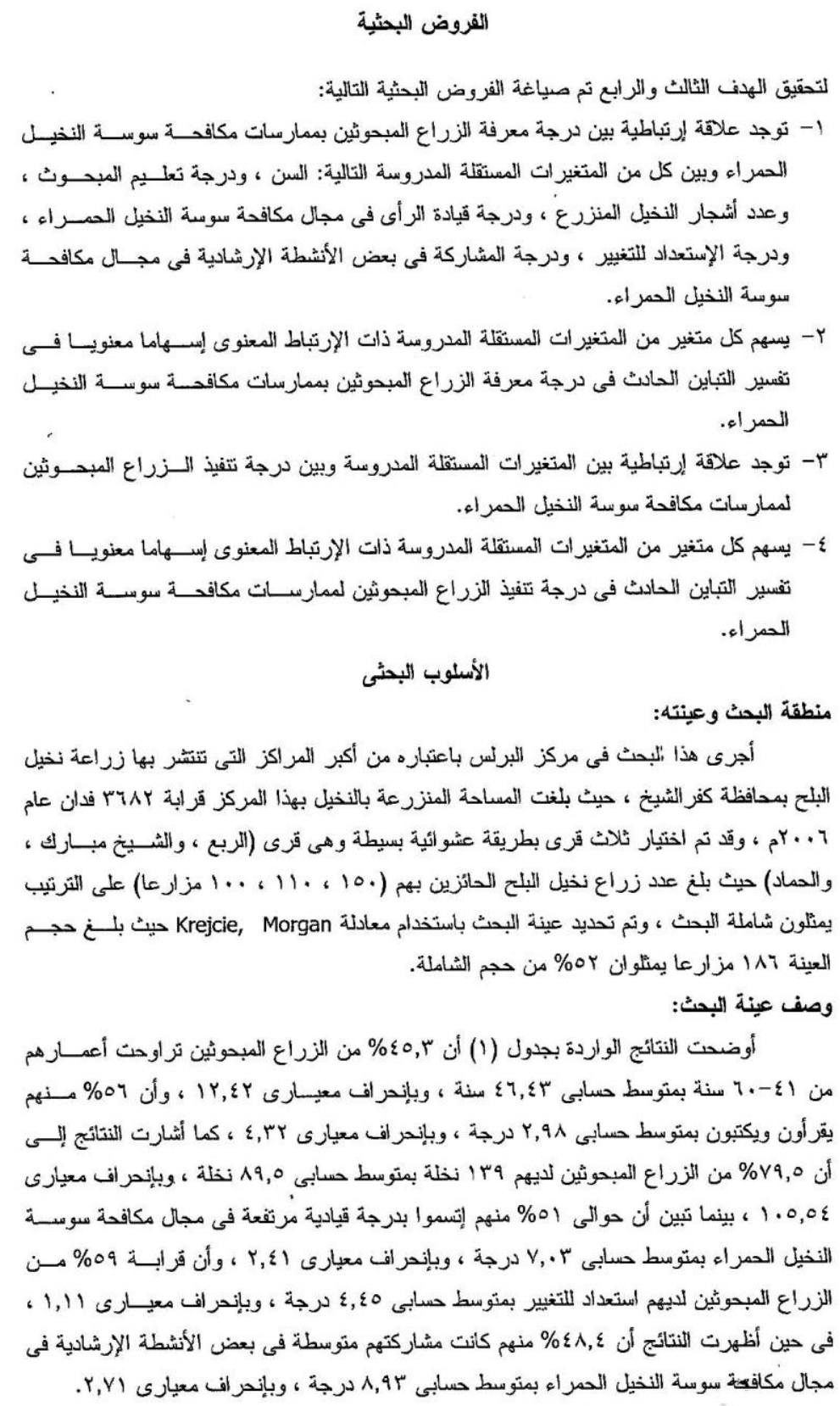


جمع وتحليل البياتات:

تم تجميع البيانات البحثية عن طريق الاستبيان بالمقابلة الشخصية لأفراد عينة البحث والتى البئي

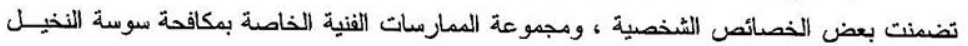

الحمر اء ، وذلك بعد إجراء الإختبار المبئى (pre-test) لبألك الاستمارة للتأكد من صلاحيتها.

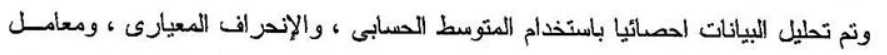

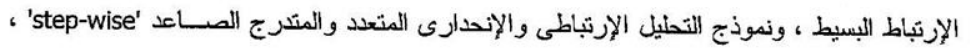
بالاضافة الى العرض الجدولى بالتكرار و النسب المئوية.

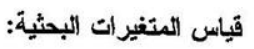

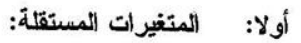

1- السن: تم قياسه بعدد سنوات سن المبحوث لأقرب سنة ميلادية وقت جمع البيانات.

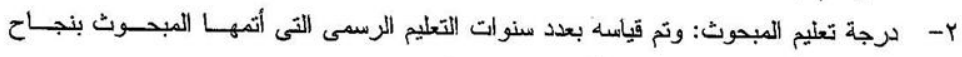

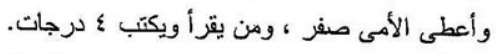

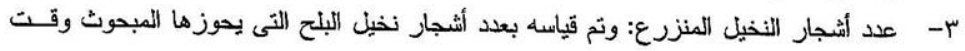
جمع البيانات.

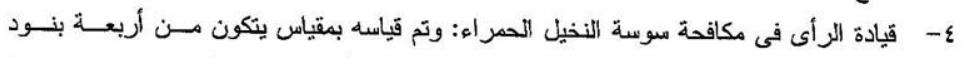

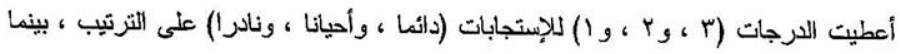

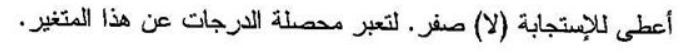

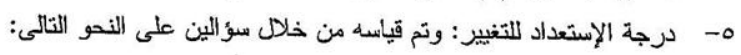

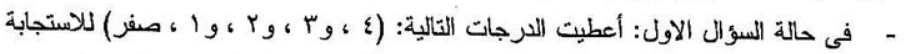

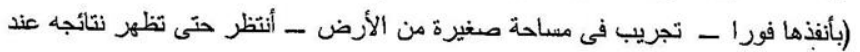

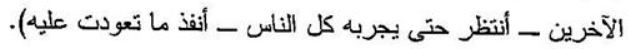

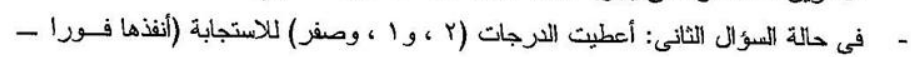

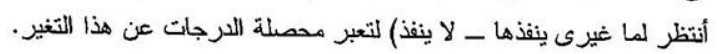

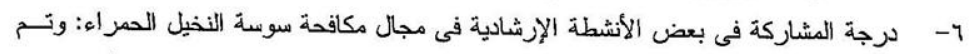

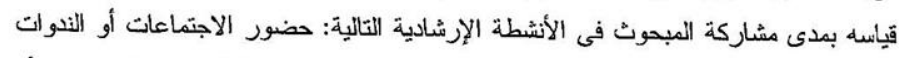

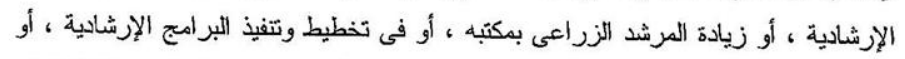

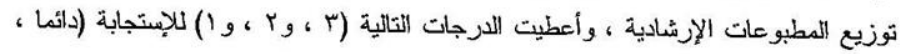

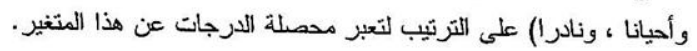

ثانيا: المتغير التابع: أ- بالنسبه لمستوى معرفة المبحوثين بممارسات مكاقحة سوسة النخيل الحمراء: ويقصد بها فى هذا البحث مدى معرفة المبحوث بمدارسات مكافحة سوسة النخيل الحمز أهاء.

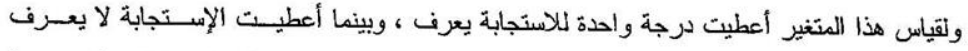

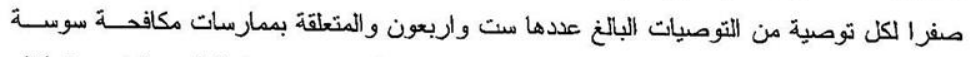

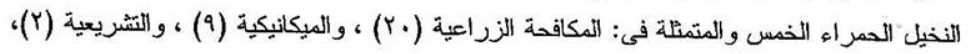


والحيوية (0)، و الكيميائية (• (1) ، ثم جمعت الدرجات لكل الممارسات الخمس السابقة مجمعة وبذلك

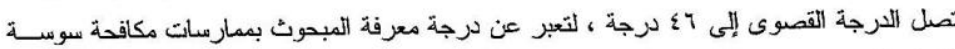

النخيل الحمر اء.

ب- بالنسبه لمستوى تنفيذ المبحوثين لممارسات مكاقحة سوسة النخيل الحمر اء:

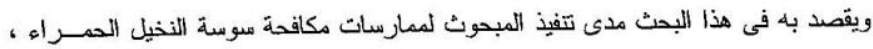

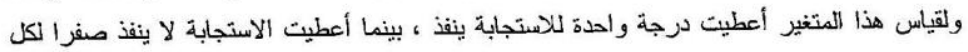

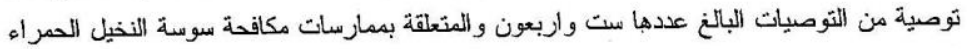

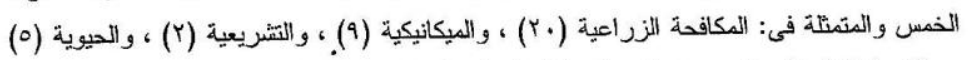

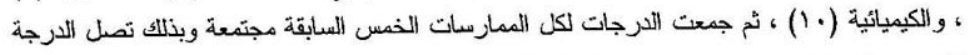
القصوى إلى 7 درجة لتعبر عن درجة تتفيذ المبحوث لممارسات مكافحة سوسة النخيل الحمراء.

\section{النتائج و المناقشة}

أولا: مستوى معرفة الزراع المبحوثين بممارسات مكافحة سوسة النخيل الحمراع:

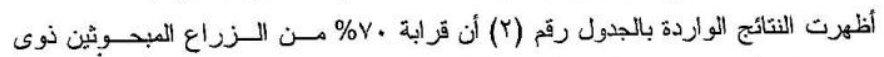

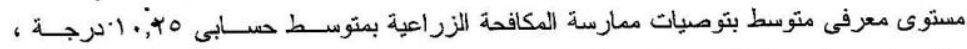

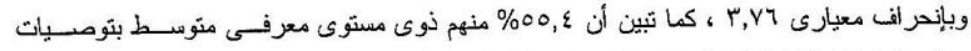

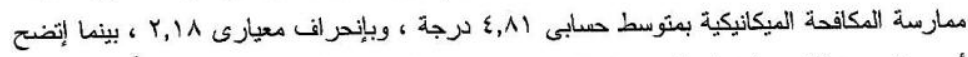

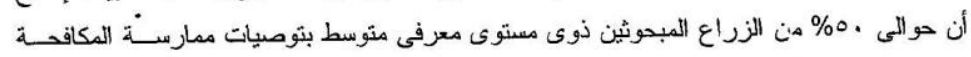

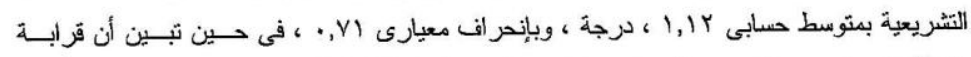

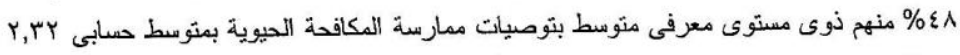

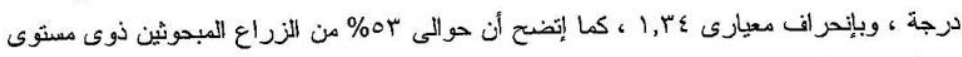

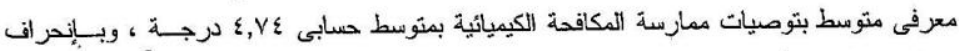

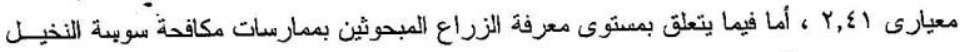

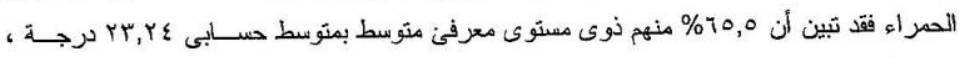

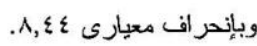
ويتضح من النتائج السابقة أن مستوى معرفة الزراع المبحوثين بممارسات مكافحة سوســة

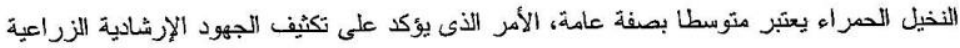
لتتمية معارف زراع نخيل البلح بتلك الممارسات المتعلقة بمكافحة هذه الآفة. 
جدول (Y): توزيع الززراع المبحوثين وفقا لمستوى معرفتهم بتوصيات ممارسات مكافحــة سوســة

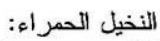

\begin{tabular}{|c|c|c|c|c|c|}
\hline الإندر اف المعيارى & المتوسط الحسابى & $\%$ & العدد العد & فئات المعرفة & م \\
\hline$r, \vee ヶ$ & $1 \cdot, y_{0}$ & $\begin{array}{l}10,0 \\
v \cdot, \cdot \\
1 \leqslant, 0\end{array}$ & $\begin{array}{l}\text { ra } \\
\text { ir. } \\
r v\end{array}$ & منتففضة (آ درجات فأقل) & 1 \\
\hline Y,IN & $\varepsilon, \wedge 1$ & $\begin{array}{l}Y \cdot, \varepsilon \\
00, \varepsilon \\
Y \varepsilon, Y\end{array}$ & $\begin{array}{l}\text { re } \\
1 . r \\
\varepsilon 0\end{array}$ & 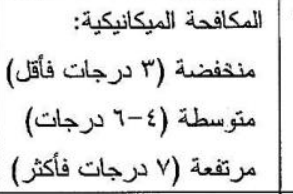 & r \\
\hline$\cdot, V_{1}$ & I,Ir & $\begin{array}{l}19, \cdot \\
0 ., \cdot \\
\text { r.,. }\end{array}$ & $\begin{array}{l}\text { ro } \\
\text { प } \\
01\end{array}$ & من لا يعرف (صفافحة التشريعية: & r \\
\hline $1, r \varepsilon$ & צ'r, & $\begin{array}{l}r \cdot, \cdot \\
\varepsilon \Lambda, \cdot \\
r r_{,}\end{array}$ & $\begin{array}{l}\text { or } \\
\text { q. } \\
\varepsilon .\end{array}$ & 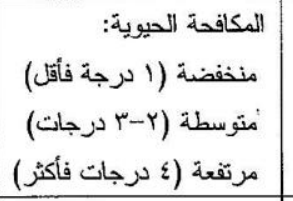 & $\xi$ \\
\hline$r, \varepsilon 1$ & $\varepsilon, V \varepsilon$ & $\begin{array}{l}\text { r.,. } \\
10, \cdot\end{array}$ & $\begin{array}{l}7 . \\
91 \\
\text { rA }\end{array}$ & |لمكافحة الكيميائية: & 。 \\
\hline$\wedge, \varepsilon \varepsilon$ & $r r, Y \varepsilon$ & $\begin{array}{l}r \varepsilon, V \\
0 Y, 0 \\
1 \wedge, \wedge\end{array}$ & $\begin{array}{l}\varepsilon 7 \\
1.0 \\
\text { ro }\end{array}$ & منوسة المعرفة بممارسات مكافحسة & 7 \\
\hline
\end{tabular}

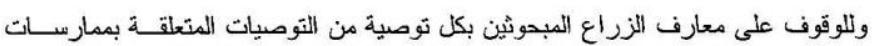

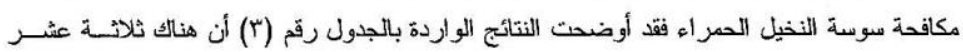

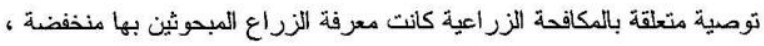


جدول ("ا): توزيع الزراع المجحوثين وفقا لمعرفتهم بكل توصبة من التوصيات المتعلقة بممارسـات

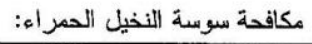

\begin{tabular}{|c|c|c|c|}
\hline$\%$ & ع العدارفين & التوصيات & p \\
\hline & & اولا: المكافحة الزيراعية: & \\
\hline$\odot \wedge, \bar{Y}$ & 1.9 & إضافة اربعة مقاطف سماد عضوى للنظلة المثُرة وغير المثُرة. & 1 \\
\hline$\bullet १, \&$ & 1.0 & إضافة 1-Yكجم سماد أزوتى لأشجار النخيل من عمر ب-入 سنوات. & r \\
\hline 00,9 & $1 \cdot \varepsilon$ & غرس الفسائل فى الأرض المستديمة بعد الفصل مباشرة. & r \\
\hline 00,9 & $1 \cdot \varepsilon$ & 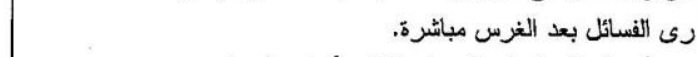 & \\
\hline $00, r$ & 1.4 & رى أشجار النخيل فى الصباح الباكر أو فى المساء. & $\circ$ \\
\hline or,, & $1 \cdots$ & 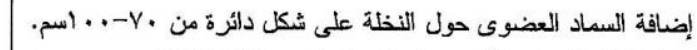 & T \\
\hline or, r & 99 & زراعة الفسائل فى الأرض المستديمة على معافة Y × Yم. & \\
\hline$\varepsilon v, \Lambda$ & $\wedge 9$ & إضافة السماد الآزوتى لأشجار النخيل غير المثمرة من شهر مارس حتى & $\wedge$ \\
\hline$\varepsilon Y, r$ & $M \Lambda$ & إضافة إثثين كجم سلفات البوتاسيوم لأشجار النذيسل مـن عمـر ب-ه & 9 \\
\hline$\varepsilon 0,1$ & $\wedge \varepsilon$ & إضافة السماد الأزوتى بالثثر حول النظلة ثم يقلب بالتربة جيدا. & \\
\hline$\varepsilon \varepsilon, \uparrow$ & ^r & إضافة ثلاثة كجم سوبر فوسفات لأشجار النخيل من عمر ب-1 سنوات. & \\
\hline$\varepsilon r, 0$ & 1) & إضافة إثنين كجم سوبر فوسفات لأشجار النخيل أكثر من ^ سنوات. & \\
\hline$\varepsilon r, \varepsilon$ & $\vee q$ & إضافة السماد الأزوتى لأشجار النخيل على ثلاث دفعات. & ז' \\
\hline ५ १, r & $v^{\mu}$ & 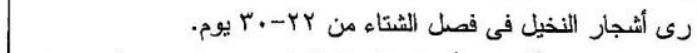 & $1 \varepsilon$ \\
\hline$r \Lambda\rangle$, & VY & إضعافة السماد الآزوتى لأشجار النخيل المثُة من شهر مسارس حتـى & 10 \\
\hline$r \wedge, \tau$ & v. & إضضافة ثلاثة كجم سلفات بوتاسيوم لأشجار النخيل أكثر من ^ شنوات. & 14 \\
\hline$r \varepsilon, q$ & 10 & الأول. الفسائل كل اربعة أيام بعد شهرين من الغرس حتـى نهايــة العـام & \\
\hline$r \varepsilon, \varepsilon$ & $T \varepsilon$ & إضافة السماد العضوى لأشجار النخيل خلال شهرى نوفمبر وديسمبر. & 11 \\
\hline$r \cdot, \varepsilon$ & 07 & تغطية الفسائل بعد الفصل عن الأم بشباك لا يزيد قطرها عن ا ملى. & \\
\hline$\nvdash \wedge, \varepsilon$ & or & إضافة اربعة كجم سماد أزوتى لأشجار النخيل أكثر من ^ سنوات. & \\
\hline \multirow{3}{*}{ OA,. } & \multirow{3}{*}{1.1} & ثاتيا: المكافحة الميكاتيكية: & \\
\hline & & التخلص من الحشائش داخل حقل النخيل بالثقاوة والجمع والحرق خارج & 1 \\
\hline & & الحقل. . & \\
\hline or, 1 & 91 & تقليم أشجار النخيل فى فصل الشتاء. & r \\
\hline 01,1 & 94 & ثقطيع الجريد الأخضر الجاف عند التقليم. ع & r \\
\hline $0 ., \cdot$ & 9 r & ثقطيع الجريد الأخضر الجاف فى الإتجاه من أسفل إلى أعلى. & $\varepsilon$ \\
\hline$\leqslant 9, \varepsilon$ & ar & إزالة النخلة شديدة الإصابة بالدفن على عمق ه, ام بالتربة. & 。 \\
\hline
\end{tabular}




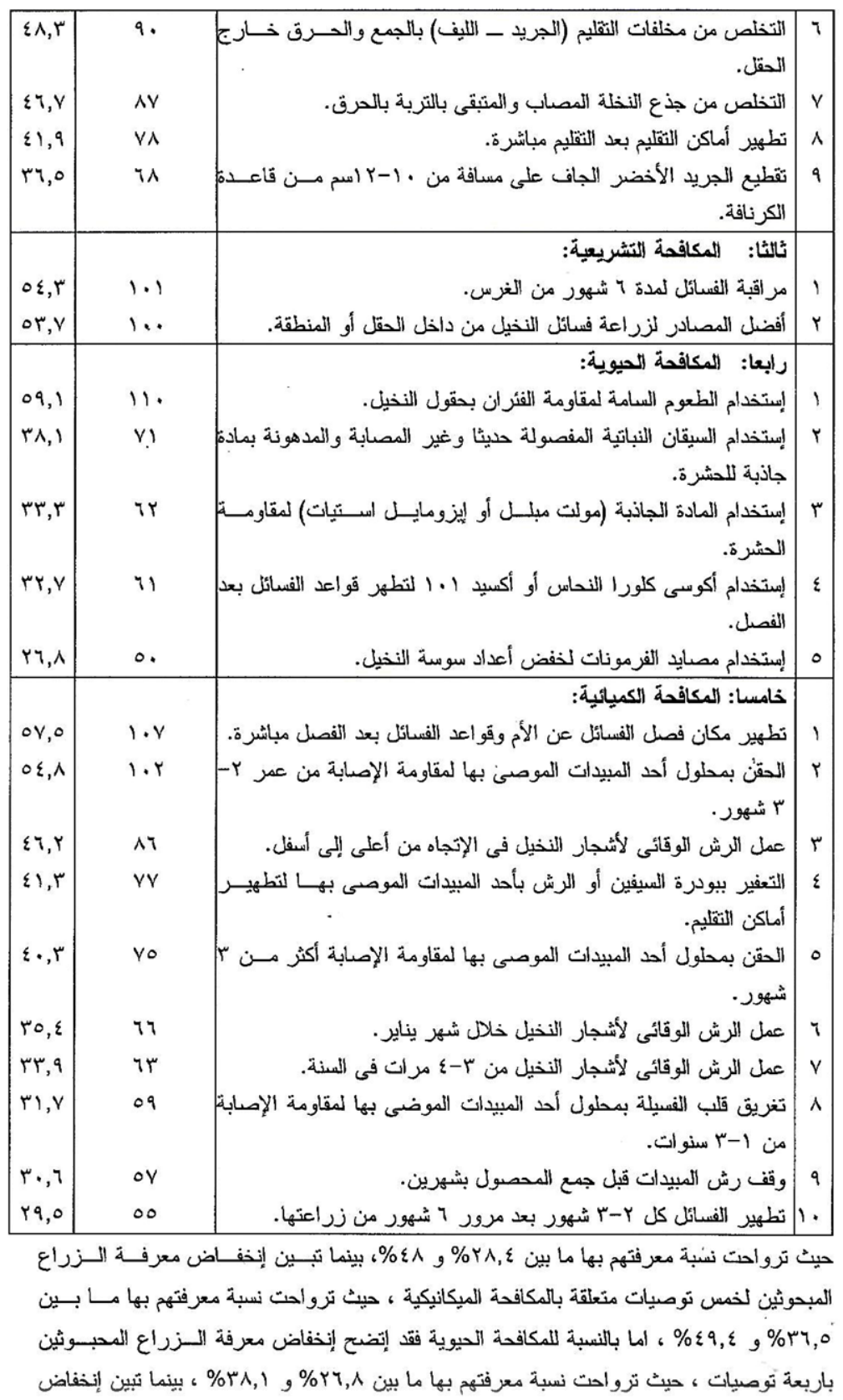


معرفة الزراع المبحوثين بثمانى نوصيات منعلقة بالمكافحة الكيميائية ، حيث ترواحت نسبة معرفتهم

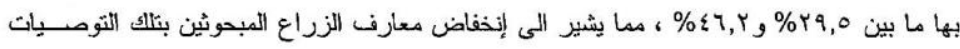

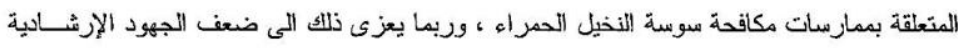

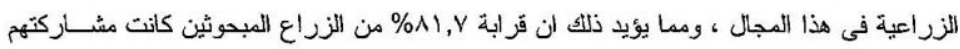

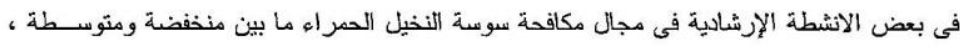

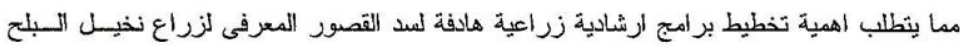

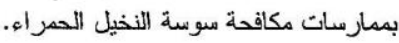

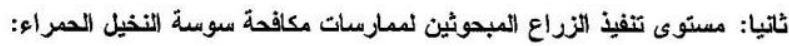

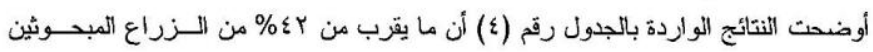

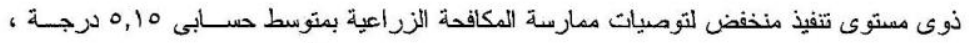

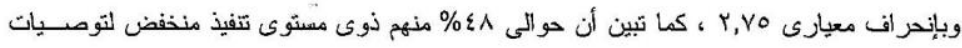

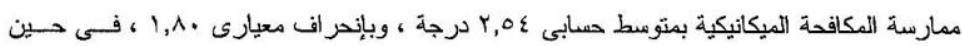

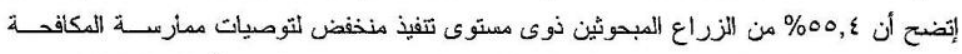

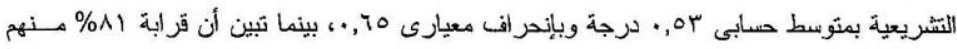

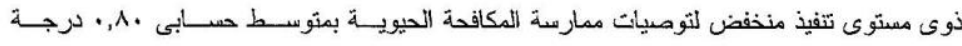

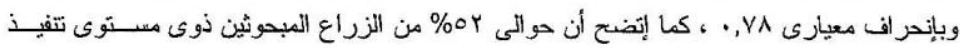

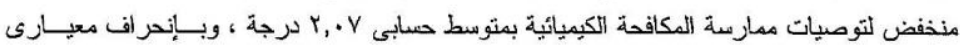

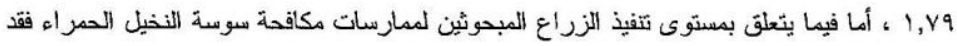

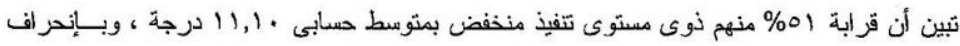
معيارى بrا,ד.

ويتضح من النتائج السابقة أن مستوى تنفيذ الزراع المبحوثين لممارسات مكافحسة سوســة

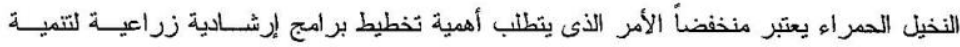
مهار ات هؤلاء الزراع ورفع مسنوى تنفيذهم لتلك الممارسات.

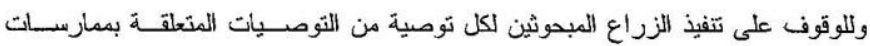

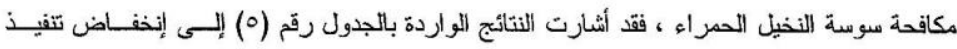

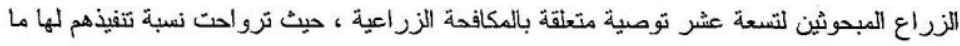

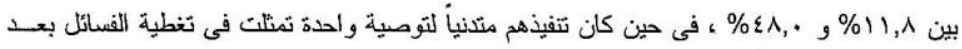

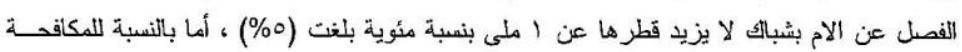

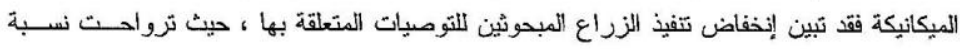

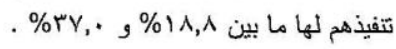




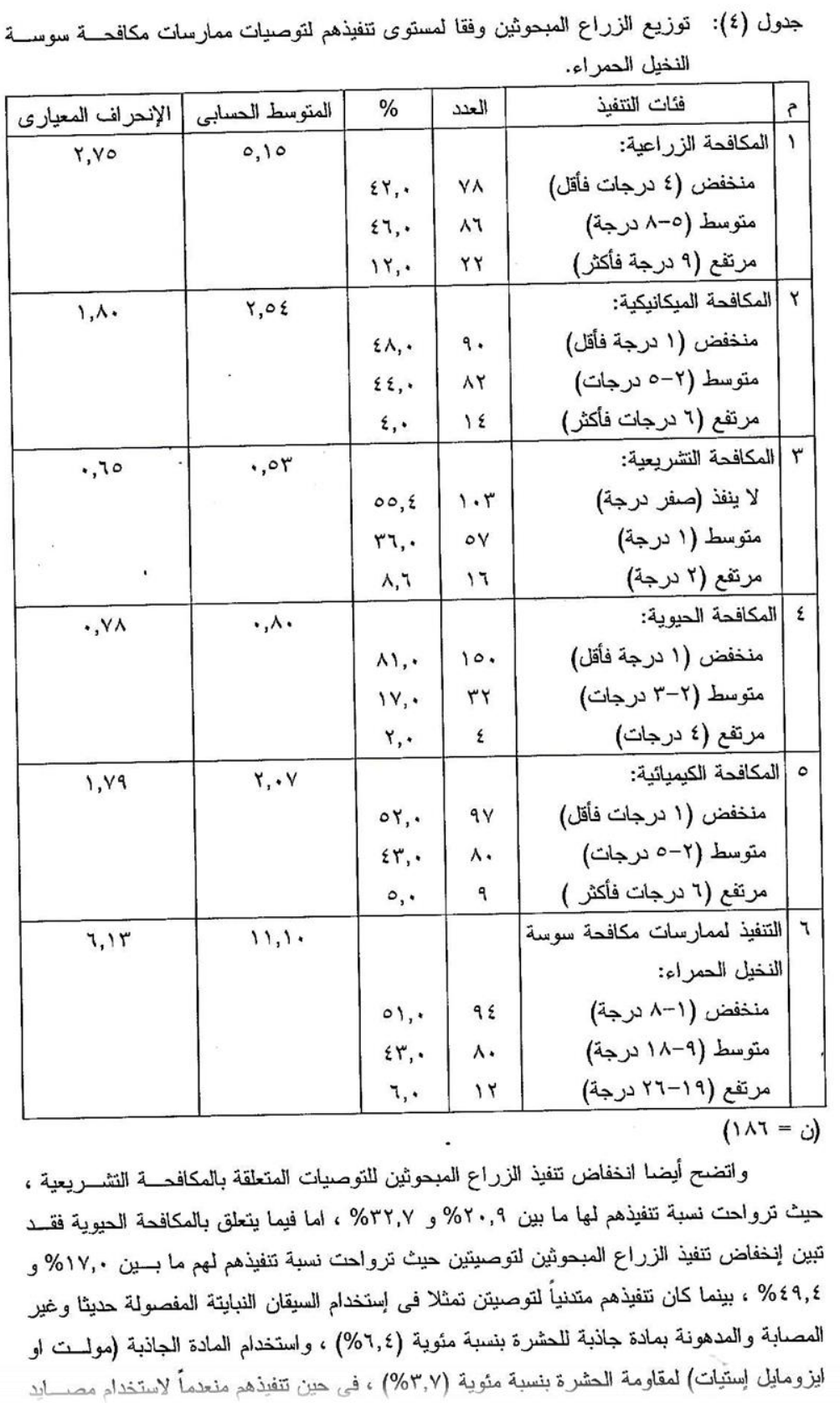




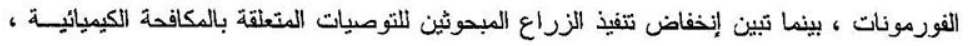

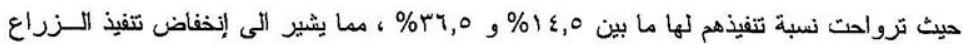

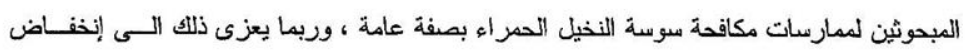

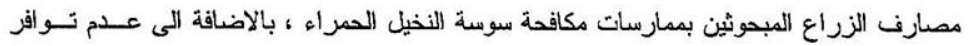

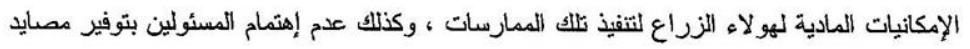
الفرمونات للكشف المبكر عن الإصابة بهذه الافة.

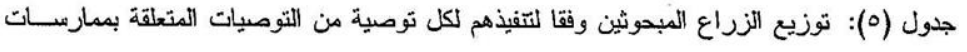
مكافحة سوسة النخيل الحمر اء.

\begin{tabular}{|c|c|c|c|}
\hline$\%$ & 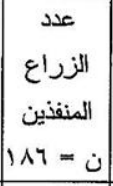 & التوصيات & s \\
\hline & & اولا: المكافحة الززراعية: & \\
\hline$\varepsilon \wedge, \cdot$ & $\wedge 9$ & إضافة اربعة مقاطف سماد عضوى للنذلة المثُمرة وغير المثرة. & 1 \\
\hline$\varepsilon 0$, & $\wedge \varepsilon$ & رى أُشجار النخيل فى الصباح الباكز أو فى المساء. & r \\
\hline rา,० & 71 & 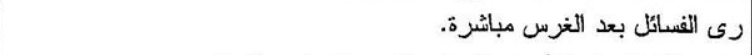 & r \\
\hline ro, & 70 & غرس الفسائل فى الأرض المستديمة بعد الفضل مباشرة. & $\varepsilon$ \\
\hline$r \cdot, \cdot$ & $0 y$ & إضافة السماد العضوى حول النظلة على شكل دائرة من • ل- . . اسم. & $\circ$ \\
\hline ५৭,० & 00 & إضافة ا-rكجم سماد أزوتى لأشجار النخيل من عمر بr-1 سنوات. & 1 \\
\hline ץ , ^ & ०. & 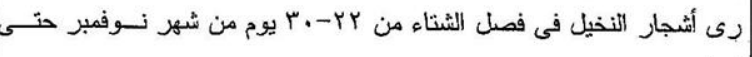 & $\mathrm{v}$ \\
\hline ץ,$\cdot$ & $\varepsilon 9$ & فربر ايرة · الفسائل فى الأرض المستديمة على مسافة V V Vم. & $\wedge$ \\
\hline$r \varepsilon$, & ¿० & | إضافة ثلاثة كجم سوبر فوسفات لأشجار النخيل أكثر من ^ سنوات. & 9 \\
\hline$r r, T$ & $\varepsilon \varepsilon$ & | إضافة اربعة كجم سماد أزوتى لأشجار النخيل أكثر من ^ سنوات. & 1. \\
\hline Yr,O & $\varepsilon r$ & إضافة السماد الآزوتى بالنثر حول النخلة ثم يقلب بالثربة جيدا. . & 11 \\
\hline rı,० & $\varepsilon$. & إضـافة السماد الآزوتى لأشجار النخيل غير المثمرة من شـــر مـــارس حنـى & ir \\
\hline$r_{\cdot}, \varepsilon$ & ra & إضافة السماد الآزوتى لأشجار النخيل على ثلاث دفعات. & ir \\
\hline$r_{\cdot}, \cdot$ & re & | إضافة السماد الآزوتى لأشجار النخيل المثرةً من شهر مارس حتى يونيو. & $1 \varepsilon$ \\
\hline $19, r$ & ry & | إضافة السماد العضوى لأشجار النخيل خلال شهزى نوفمبر وديسمبر . & 10 \\
\hline $\mathrm{IV}, \cdot$ & r & | إضافة إنين كجم سوبر فوسفات لأشجار النخيل أكثر من ^ سنوات. & 14 \\
\hline 17,7 & r & |رى الفسائل بعد شهرين من الغرس كل ع أيام حتى نهاية العام الأول. & iv \\
\hline $17, \cdot$ & r. & | إضافة إثنين كجم سنفات البوثأسيوم لأشجار النخيل من عر ب-1 سنوات. & is \\
\hline 11,1 & rr & | إضافة ثلاثة كجم سلفات البوثاسيوم لأشجار النخيل أكثر من ^ سنوات. & 19 \\
\hline $0, \cdot$ & $1 \cdot$ & |تغطية الفسائل بعد الفصل عن الآم بشبالك لا يزيد قطر ها عن ا ملى. & \\
\hline
\end{tabular}


تابع جذول (0)

\begin{tabular}{|c|c|c|c|}
\hline$r_{\Lambda},$. & 79 & |ثقليم أشجار النخيل في المكافحة الميكانيكية: & 1 \\
\hline$r \varepsilon_{1}$. & $7 \varepsilon$ & تقطيع الجريد الأخضر الجاف عند التقليم. & r \\
\hline$r \cdot, 4$ & or & التخلص من الحشاشُ داخل حقل النخيل بالنقاوة والجمع والحرق خارج الحقل. & r \\
\hline r৭, & $0 \varepsilon$ & تقطيع الجريد الأخضر الجاف فى الإتجاه من أسفل إلى أعلى. . & $\varepsilon$ \\
\hline YA, $\cdot$ & ro & إزالة النظلة شديدة الإصابة ثم الدفن على عمق ه, ام بالتربة. & $\circ$ \\
\hline Yo,. & $\varepsilon Y$ & التخلص من جذع النخلة المصاب و المثبقى بالتربة بالحرق. & 1 \\
\hline rщ, & « & |تطهير أماكن النقليم بعد النقليم مباشرة. & $\mathrm{v}$ \\
\hline $1 \wedge, \wedge$ & ro & تقطيع الجريد الأخضر الجاف على مسافة من ـ 1- ب اسم من قاعدة الكرنافة. & $\wedge$ \\
\hline $1 \wedge, \wedge$ & ro & التخلص من مخلفات الثقليم (الجريد ـ الليف) بالجمع والحرق خارج الحقل. & 9 \\
\hline & & |ثالثا: : المكاقحة التشريعية: & \\
\hline rY, & 71 & |مر اقبة الفسائل لمدة 7 شهور بعد الغرس. & 1 \\
\hline$r \cdot, 9$ & rq & أفضل المصادر لزراعة فسائل النخيل من داخل الحقل أو المنطقة. & r \\
\hline & & 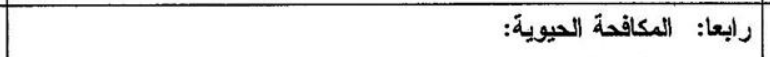 & \\
\hline$\varepsilon १, \varepsilon$ & 94 & إستخدام الطعوم السامة لمقاومة الفئران بحقول النخيل. . & 1 \\
\hline IY, & rr & إستخدام أكوسى كلورا النحاس أو أكسيد 1. ألتطهر قو اعـد الفسـائل بعـد & r \\
\hline & & الفصل. . & \\
\hline $7, \varepsilon$ & ir & إستخدام السيقان النباتية المفصولة حديثا وغير المصابة والمدهونة بمادة جاذبة & r \\
\hline & & للحشرة. & \\
\hline r, $\Lambda$ & $\mathrm{v}$ & إستخدام المادة الجاذبة (مولت مبلل أو إيزومايل إسيتات) لمقاومة الحشرة. & $\varepsilon$ \\
\hline- & - & استخدام مصايد الفرومونات & ○ \\
\hline & & 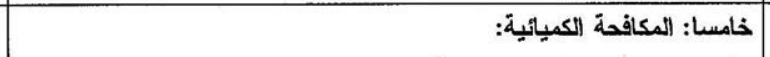 & \\
\hline ז,० & IV & تطهيز مكان فصل الفسائل عن الأم وقو اعد الفسائل بعد الفصل مباشرة. & 1 \\
\hline r৭, & $0 \leqslant$ & عمل الرش الوقائى لأشجار النخيل فى الاتجاه من أعلى إلى أسفل. . & r \\
\hline$r_{0, \Lambda}$ & $\varepsilon \wedge$ & التعفير بيودرة السيفين أو الرش بأحد المبيدات الموصى بها لتطهيـر أمــاكن & r \\
\hline & & 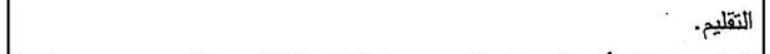 & \\
\hline$r \varepsilon, 1$ & «o & الحقن بمحلون أحد المبيدات الموصى بها لمقاومة الإصــابة مـن عمـر ب-r & $\varepsilon$ \\
\hline & & سنوات. . & \\
\hline rr, & $\varepsilon r$ & الحقن بمحلول أحد المبيدات الموصى لمقاومة الإصابة أكثر من ب شهور. . & $\circ$ \\
\hline rr,o & $\varepsilon Y$ & تغريق قلب الفسيلة بمحلول أحد المبيدات الموصىى لمقاومة الإصابة من عمسر & T \\
\hline & & 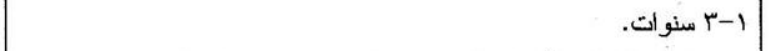 & \\
\hline $1 \wedge$, & ऍ & عمل الرش الوقائى لأشجار النخيل من ب-ـ مرات فى السنة. & $\checkmark$ \\
\hline$i v, v$ & r & عمل الرش الوقائى لأشجار النخيل خلال شهر يناير. & $\wedge$ \\
\hline 10,0 & rq & وقف رش المبيدات قبل جمع المحصول بشهرين. & 9 \\
\hline $1 \varepsilon, 0$ & rV & | تطهير الفسائل كل Y-r شهور بعد مرور 1 شهور من زر اعتها. & 1. \\
\hline
\end{tabular}


مما يؤكد حتمية بذل الجهود الإرشادية الزر اعية بهدف إحداث التغيرات السئوكية المرغوبة

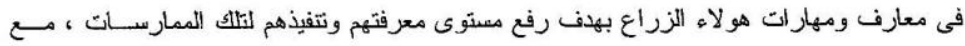

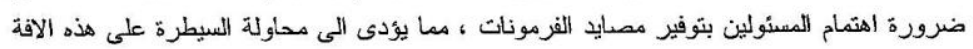

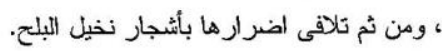

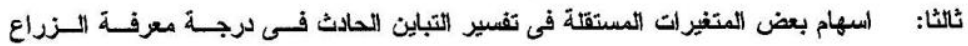

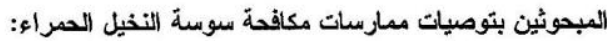

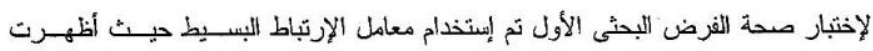

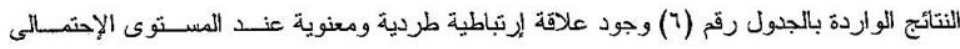

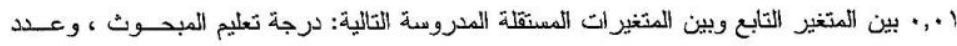

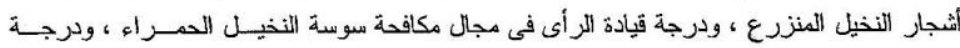

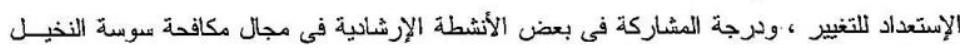

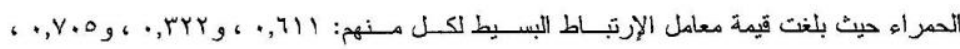

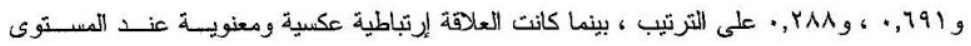

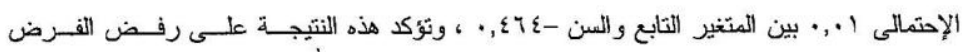

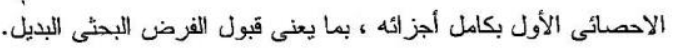

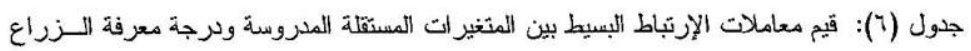
المبحوثين بتوصيات ممارسات مكافحة سوسة النخيل الحمر اءعراء.

\begin{tabular}{|c|c|c|}
\hline معامل الإرتباط & المتغيرات المستقلة & s \\
\hline$\because \cdot, \varepsilon 7 \varepsilon-$ & 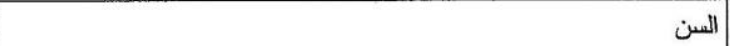 & 1 \\
\hline$\because, 7 ו 1$ & |درجات تعليم المبحوث & r \\
\hline "•rrrr & | عدد أشجار النخيل المنزرع & r \\
\hline$\because \cdot, \vee, ०$ & درجة قيادة الر أى فى مجال مكافحة سوسة النخيل الحمر اء & $\varepsilon$ \\
\hline$\because \cdot 791$ & |درجة الإستعداد للتغيير & $\circ$ \\
\hline •. & درجة المشاركة فى بعض الأنشطة الإرشادية فى مجــال مكافحــة سوســة & 7 \\
\hline n & النخيل الحمر اء & 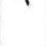 \\
\hline
\end{tabular}

• معنوية عند المستوى الإحتمالى 0.,..

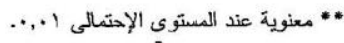

r

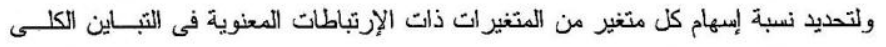

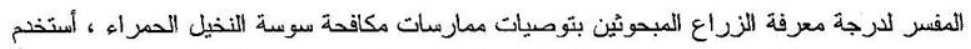

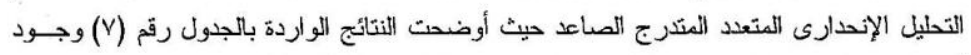

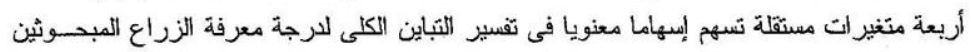

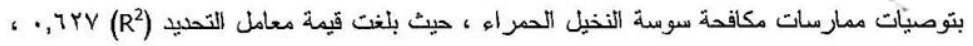


جدول (^): قيم معاملات الإرتباط البسيط والإنددار الجزئى بين المتغيرات المستقلة المدروسة وبين

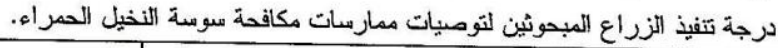

\begin{tabular}{|c|c|c|}
\hline معامل الإرتباط البسيط & المتغيرات المسنقلة & م \\
\hline$\because, r \Lambda r-$ & 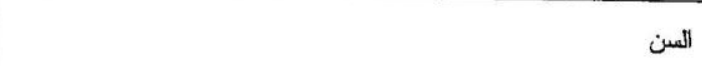 & 1 \\
\hline$\because \cdot, 099$ & درجات تعليم المبحوث & r \\
\hline$\because, r Y I$ & عدد أشجار النخيل المنزرع & r \\
\hline 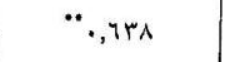 & درجة قيادة الر أى فى مجال مكافحة سوسة النخيل الحمراء & $\varepsilon$ \\
\hline$\because$, VYr & درجة الإستعداد للتغيير & 。 \\
\hline$\because, 19 \varepsilon$ & دالنيل الحمرة المشاركة فى بعض الأنشطة الإرشادية فى مجال مكافحسة سوسـة & 1 \\
\hline توى الإحتمالى 0 •., & 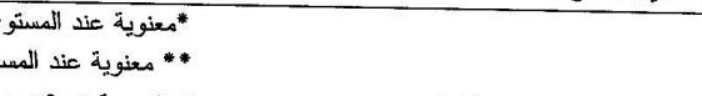 & \\
\hline
\end{tabular}

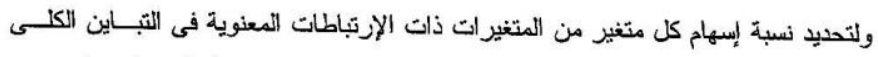

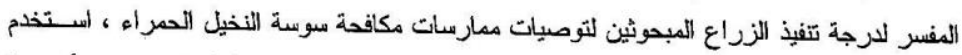

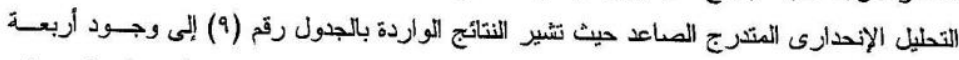

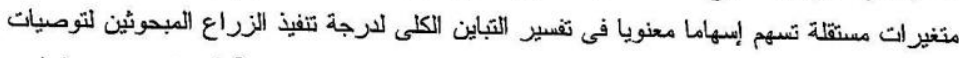

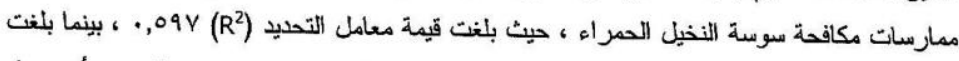

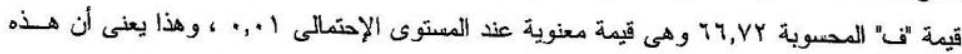

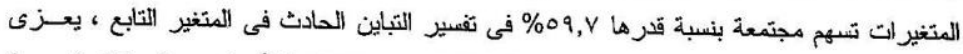

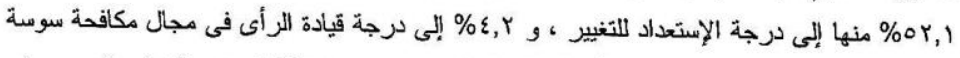

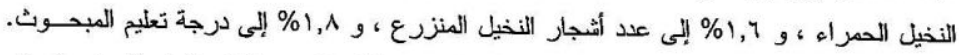

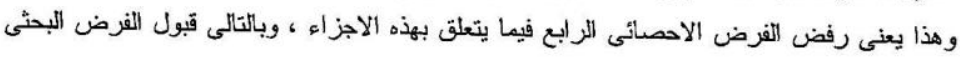
البديل فيما يتعلق بكل منها. 
جدول (9): نتائج التحليل الإرنباطى و الإنحدارى المتعدد المتدرج الصاعد للعلاقة بين المتغيــرات

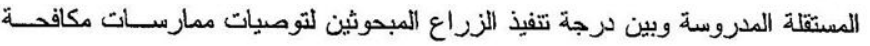

\begin{tabular}{|c|c|c|c|c|c|}
\hline & & & \multicolumn{3}{|c|}{ سوسة النخيل الحمر اء. } \\
\hline قيمة "ت" & معامل الإنحدار & اللتباين المفسبر المئوية & اللتباين المفسية النسبة & المتغير الداخل فى التحليل & b \\
\hline $4,9$. & $r, O V$ & OY, I & $\cdot, 0 Y 1$ & |درجة الإستعداد للتغيير & 1 \\
\hline וז,r, & $\cdot, \leqslant Y$ & $\varepsilon, r$ & מיט & مكافحة سيادة الرأى فى مجـيل الحمراء & r \\
\hline • ع & 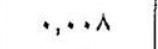 & 1,7 & $\cdot, 0 \vee 9$ & عدد أشجار النخيل المنزرع & $r$ \\
\hline •r, r & $\cdot, r V$ & 1,1 & $\cdot, 09 \mathrm{~V}$ & درجة تعليم المبحوث & $\varepsilon$ \\
\hline$\cdot$, & $5+2.09$ & معنوية عند & & 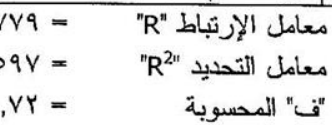 & قيمة قيمة \\
\hline
\end{tabular}

ومما سبق ينضح ضرورة أخذ المتغيرات التى أظهر البحث إسهامها فى درجة تثفيذ الزرراع المبحوثين لتوصيات ممارسات مكافحة سوسة النخيل الحمر اء فى الإعتبار مستقبلا عند تخطيط برامج إرشادية زر اعية تستهدف تتمية مهارت زراع نخيل البلح لتنفيذ تلك الممارسات.

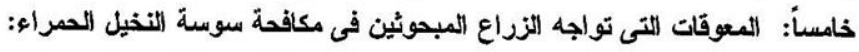

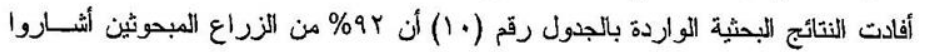

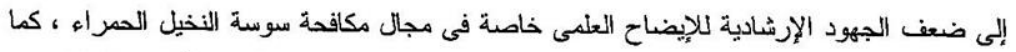

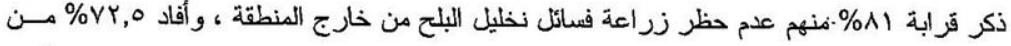

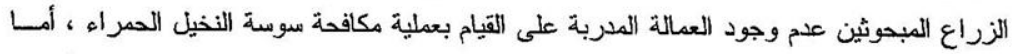

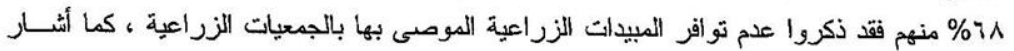

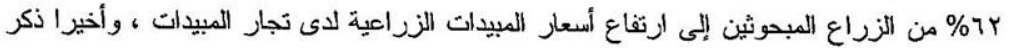
\% منهم عدم توافر مصايد الفرمونات.

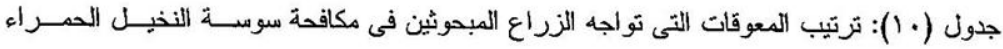
تتازليا وفقا لنسب ذكر ها من جانبهم

\begin{tabular}{|c|c|c|c|}
\hline$\%$ & - العدد & المعوقات & s \\
\hline $9 Y$ & IVr & 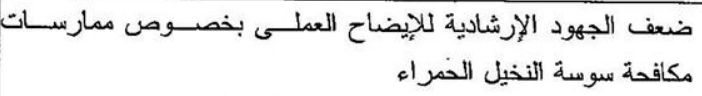 & 1 \\
\hline 11 & 10. & عدم حظر زر اعة فسائل نخيل البلح من خارج المنطقة & r \\
\hline$V r, 0$ & 1ro & الحمر وجود العمالة المدربة على الققيام بعملية مكافحة سوســـة النخيــل & r \\
\hline 41 & IYY & عدم توافر المبيدات الززراعية الموصى بها بالجمعيات الزراعية. & $\varepsilon$ \\
\hline זי & 110 & ارتقاع أسعار المبيدات الزراعية لدى تجار المبيدات & $\circ$ \\
\hline 00 & 1.4 & عدم تو افر مصايد الفرمونات. & 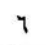 \\
\hline
\end{tabular}


سادساً: مقترحات الزراع المبحوثين لنجابه المعوقات التى تو اجهوم فى مكاقحة سوســة النخيـل

الحمر اءء:

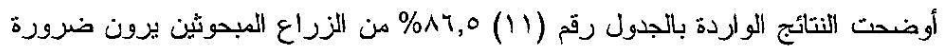

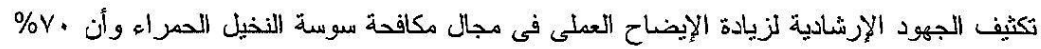

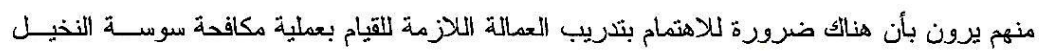

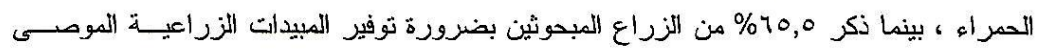

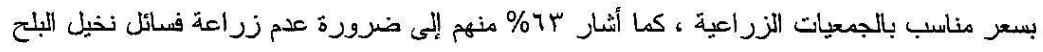

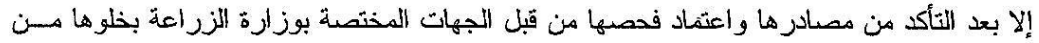

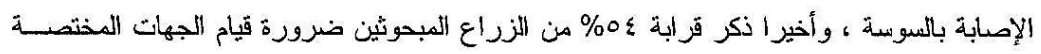

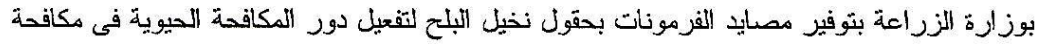

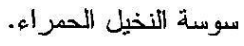
جدول (1): رتيب مقترحات الزراع المحبوثين لمجابهة المعوفات التى تواجههم فى مكافحة سوسة

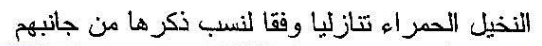

\begin{tabular}{|c|c|c|c|}
\hline$\%$ & العدد (ن = الن ) & 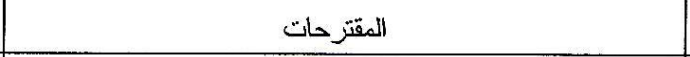 & م \\
\hline \multirow[t]{2}{*}{$\Lambda \uparrow, 0$} & 171 & تكثيف الجهود الإرشادية لزيادة الإيضاح العملى فى هجال مكافـة & 1 \\
\hline & & اسوسة النخبل الحمراء. & \\
\hline \multirow[t]{2}{*}{$\mathrm{v}$. } & $|r|$ & 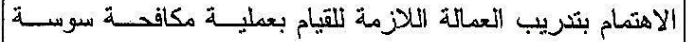 & r \\
\hline & & | النخيل الحمراء. & \\
\hline \multirow[t]{2}{*}{70,0} & Irr & لتوافر المبيدات الزراعية الموصى بها بسعر مناسب بالجمعيـات & r \\
\hline & & |الزر اعية. & \\
\hline \multirow[t]{2}{*}{ r } & $11 \mathrm{v}$ & التأكد من مصادر زراعة فسائل النخيل و اعتمادها من قبل الجهات & $\varepsilon$ \\
\hline & & |لمختصة بوزارة الزر اعة بخلو ها من الإصابة بالسوسة. & \\
\hline $0 \xi$ & $1 \cdots$ & |توافر مصايد الفرمونات لتفعيل دور المكافحة الحيوية. & . \\
\hline
\end{tabular}

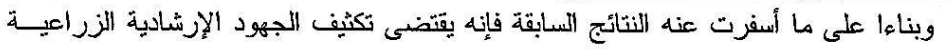

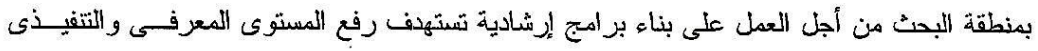

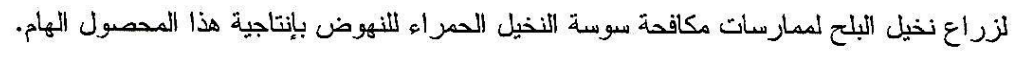




\begin{tabular}{|c|c|c|c|c|c|}
\hline \multicolumn{6}{|c|}{ 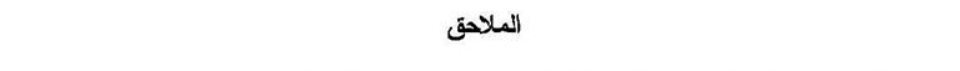 } \\
\hline الإندر اف المعيارى & المتوسط الحسابى & $\%$ & العدد & الخصائص. & 5 \\
\hline$I Y, \varepsilon Y$ & $\varepsilon \nearrow, \varepsilon \mu$ & $\begin{array}{l}r o, \cdot \\
0 \varepsilon, r \\
1 \cdot, V\end{array}$ & $\begin{array}{l}10 \\
1.1 \\
5 .\end{array}$ & 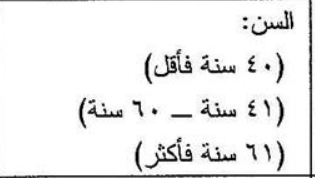 & 1 \\
\hline$\varepsilon, \mu^{\prime}$ & Y,१^ & $\begin{array}{l}Y \varepsilon, Y \\
07,0 \\
r, \Lambda \\
r, Y \\
Y, 0 \\
0, \varepsilon\end{array}$ & $\begin{array}{l}\varepsilon 7 \\
1.0 \\
v \\
\varepsilon \\
1 \varepsilon \\
1 .\end{array}$ & درجة نعيم المبحوث: & r \\
\hline $\begin{array}{c}1.0, r \varepsilon \\
.\end{array}$ & 19,10 & $\begin{array}{l}v 9,0 \\
1 r, . \\
v, 0\end{array}$ & $\begin{array}{l}1 \leqslant \wedge \\
r \varepsilon \\
1 \varepsilon\end{array}$ & 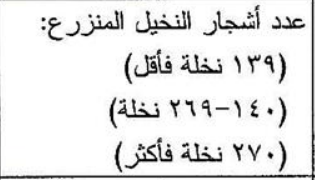 & $r$ \\
\hline$r, \varepsilon)$ & $\mathrm{V}, \cdot \mathrm{r}$ & $\begin{array}{l}0, \varepsilon \\
\varepsilon r, 0 \\
01,1\end{array}$ & $\begin{array}{l}1 . \\
11 \\
90\end{array}$ & 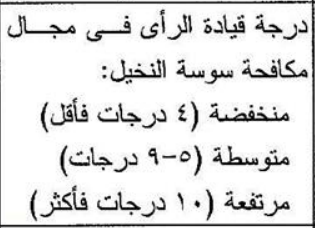 & $\varepsilon$ \\
\hline 1,11 & $\varepsilon, \varepsilon 0$ & $\begin{array}{l}r, \cdot \\
r i, \cdot \\
09, .\end{array}$ & $\begin{array}{c}\varepsilon \\
V Y \\
11 .\end{array}$ & 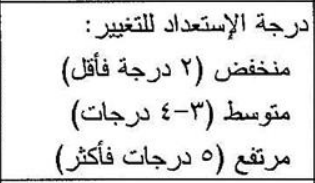 & 0 \\
\hline$Y, Y I$ & $\wedge, १$ & $\begin{array}{l}r, r \\
\varepsilon \Lambda, \varepsilon \\
\mid \wedge, r\end{array}$ & $\begin{array}{l}7 r \\
q . \\
r \varepsilon\end{array}$ & 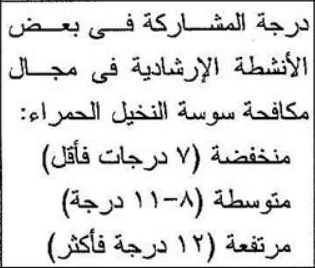 & T \\
\hline
\end{tabular}


المراجيع

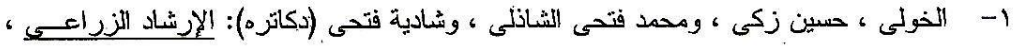

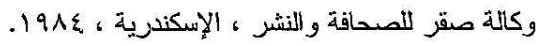

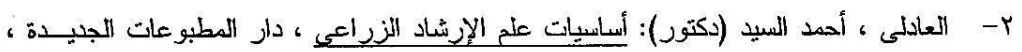

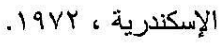

ץ- حجازى ، مصطفى كمال (دكتور) ) انتاج محاصيل الفاكهة المستديمة الخضــرة و المتنــاقطة

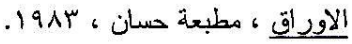

ع- صالح ، صبرى مصطفى ، ومحمد عمر الطنوبى ، وسهير محمد عزمى (نكاتره): الإرشــاد

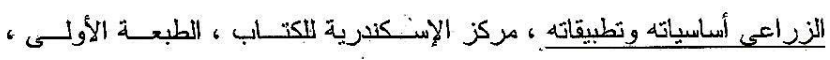

$\because$. r...

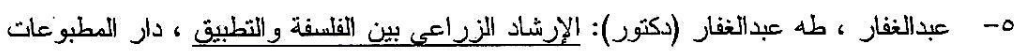

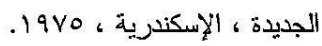

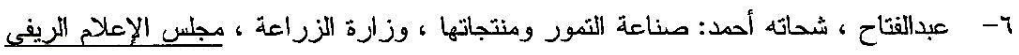

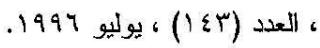

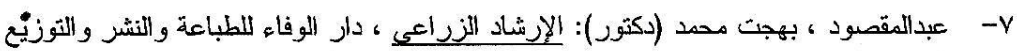

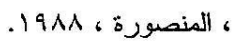

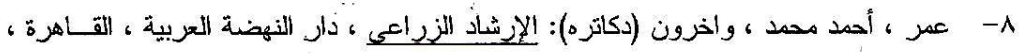
$.19 \mathrm{rr}$

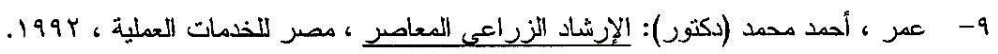

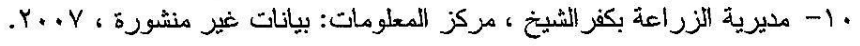

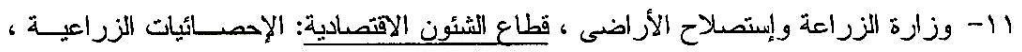

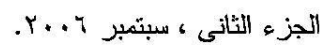

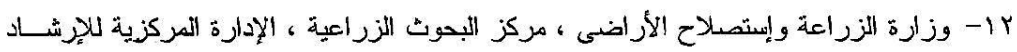

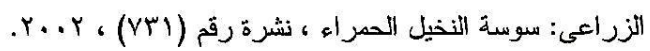

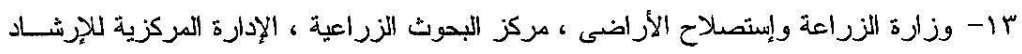

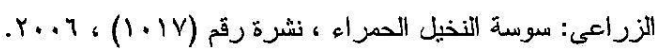

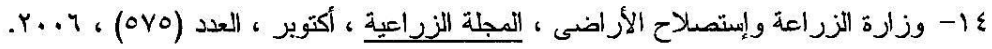

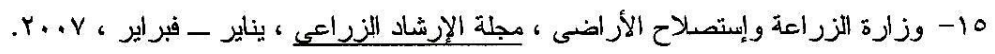

16. Rogers, E.M., and Shoemaker F.F.: Communication of innovation: Across Cultural Approach, $2^{\text {nd }}$ ed the Free Press, New York, U.S.A., 1971. 


\title{
FARMERS' KNOWLEDGE AND IMPLEMENTATION REGARDING PRACTICES OF DATE PALMS WEEVIL CONTROL AT EL- BROLLOUS DISTRICT IN KAFR EL-SHEIKH GOVERNORATE
}

\author{
SHADI A. M. EL- TANTAWI
}

Agricultural Extension and Rural Development Research Institute, ARC, Giza

(Manuscript received 6 August 2007)

\begin{abstract}
This research aimed at identifying data palm farmers knowledge and implementing levels with practices of date-palms weevil control, determining the correlation relationship between each of the dependent variables and the other independent variables as well as determining the contribution of independent variables in explaining total variance of each depended variables, and to identify the constraints facing respondents in this field and their suggestions to overcome them point of view from their.

Study data were collected from systematic random sample amounting 186 respondents were selected among date-palm farmers in El-Brollous district by using personal interview questionnaire during April 2007 frequencies, percentages simple correlation coefficient, and multiple correlation and regression analysis (step-wise) were used for analyzing data statistically.
\end{abstract}

The most important findings of this study revealed that:

1. It was found that the knowledge level of $56.5 \%$ of respondents with the practices of control date palm weevil were moderate, nearly $51 \%$ of them their implementation are generally town fro these studied practices (agricultural practices, mechanical, legal, biological and chemical control).

2. Independent variables explained $63.7 \%$ from the total variance of farmer respondents knowledge degree with practices of date palm weevil control. These variables were degree of opinion leadership in field of date palm weevil control $(49.7 \%)$, number of cultivated date palm trees $(8.3 \%)$ and degree of respondents education (1.8\%).

3. It was found that the independent variables explained $59.7 \%$ from the total variance of respondents implementing for practices of control date palm weevil. Degree of opinion leadership in field of date palm weevil control (4.2\%), number of cultivated date palm trees $(1.6 \%)$, and degree respondents education $(1.8 \%)$.

4. There were six constraints facing respondents related to field of control date palm weevil as follows: weakness of extension efforts about demonstration concerning control of date palm weevil $(92 \%)$, cultivation of date palm transplants from out of the area $(81 \%)$, absence of trained (qualified) workers required for implementing treatments of control $(72.5 \%)$, insufficient of recommended pesticides in agricultural co-operation societies (68\%), high prices of pesticides (62\%) and lack of insect tops (phytoseanitation) (55\%). 